\title{
Criminologia Crítica, Feminismo e Interseccionalidade na Abordagem do Aumento do Encarceramento Feminino
}

\author{
Idilva Maria Pires Germano ${ }^{1}$ \\ Rebeca Áurea Ferreira Gomes Monteiro ${ }^{1}$ \\ ${ }^{1}$ Universidade Federal do Ceará, CE, Brasil. \\ ${ }^{1}$ Universidade Federal do Ceará, CE, Brasil. \\ Mariana Tavares Cavalcanti Liberato ${ }^{1}$ \\ ${ }^{1}$ Universidade Federal do Ceará, CE, Brasil.
}

Resumo: Desde 2000 a população carcerária feminina no Brasil vem crescendo em ritmo preocupante, lotando as prisões em todos os estados da Federação. Este trabalho discute a criminalização de mulheres a partir de uma ótica interseccional, realçando a intersecção de gênero, raça-etnia, pobreza e outras fontes de subordinação como central para entender e enfrentar o problema. Foram analisadas taxas de encarceramento e o perfil sociodemográfico da população carcerária feminina no país e na América Latina, divulgadas em documentos públicos oficiais. Os dados foram interpretados a partir de princípios da criminologia crítica feminista e do pensamento interseccional e à luz de uma literatura crítica nacional e internacional sobre a criminalização e o encarceramento em massa, especialmente de mulheres jovens, negras e pobres. Feminização da pobreza, discriminação racial e de gênero, política de guerra às drogas, inchação do Estado Penal entre outros fatores interligam-se e resultam no encarceramento seletivo de jovens entre 18 a 33 anos, declaradas negras ou pardas, com ensino fundamental incompleto, respondendo por tráfico de drogas (flagradas com pequena quantidade de drogas), mães solteiras. Nosso argumento é que a perspectiva da interseccionalidade permite superar a análise descritiva e estanque dos fatores envolvidos em crimes cometidos por mulheres e seu consequente encarceramento, esclarecendo como o sistema penal pode incorporar e perpetuar formas naturalizadas de controle dos corpos femininos e a injustiça social. Concluímos que o olhar interseccional ilumina as complexas situações biográficas e vivências cotidianas de opressão que afetam cerca de 45 mil mulheres em prisões brasileiras hoje.

Palavras-chave: Encarceramento Feminino; Interseccionalidade; Criminologia Feminista. 


\title{
Critical Criminology, Feminism and Intersectionality to Approach the Rise of Female Incarceration
}

\begin{abstract}
Since 2000 the population of incarcerated women in Brazil has risen in a fast and disturbing pace resulting in crowded prisons in each state of the country. This paper discusses the female criminalization adopting an intersectional approach, underlining the intersection of gender, race-ethnicity, poverty and other sources of social subordination as central to understand and face the problem. Rates of female incarceration and the sociodemographic profile of female population in prisons in Brazil and Latin America as published in oficial documents were analysed. The data were interpreted on the basis of the tenets of critical feminist criminology and intersectional thought and with the support of a national and international critical literature on mass criminalization and incarceration, specially of young, black and poor women. Feminization of poverty, racial and gender discrimination, war against drugs policies, rise of a Penal State, among other factors interconnect and result in selective incarceration of 18 to 33 year old young women, of black and brown color, of low incomplete primary education, prosecuted for drug trafficking (caught carrying small amounts of drugs), single mothers. We argue that intersectionality allows us to overcome the descriptive and isolated analysis of the factors involved in crimes comitted by women and their imprisonment clarifying how penal system can incorporate and reproduce naturalized forms of control of female bodies and social injustice. We conclude that the intersectional gaze enlightens the complex biographical situations and daily experiences of oppression that impair nearly 45 thousand women in Brazilian prisons today.
\end{abstract}

Keywords: Female Incarcarceration; Intersectionality; Feminist Criminology.

\section{Criminología Crítica, Feminismo e Interseccionalidad en el Abordaje del Aumento del Encarcelamiento Femenino}

Resumen:Desde2000 la población carcelaria femenina en Brasil viene creciendo a ritmo preocupante, llenando las prisiones en todos los estados del país. Este trabajo discute la criminalización de mujeres desde una óptica interseccional, destacándola intersección de género, raza-etnia, pobreza y otras fuentes de subordinación como central para entender y enfrentar el problema. Se analizaron tasas de encarcelamiento y el perfil sociodemográfico de la población carcelaria femenina en el país y en América Latina, divulgadas en documentos públicos oficiales. Los datos fueron interpretados a partir de principios de la criminología crítica feminista y del pensamiento interseccional y a la luz de una literatura crítica nacional e internacional sobre la criminalización y el encarcelamiento masivo, especialmente de mujeres jóvenes, negras y pobres. Feminización de la pobreza, discriminación racial y de género, política de guerra a las drogas, hinchazón del Estado Penal entre otros factores se interrelacionan y resultan en el encarcelamiento selectivo de jóvenes entre 18 a 33 años, declaradas negras o pardas, con enseñanza fundamental incompleta, respondiendo por tráfico de drogas (flagradas con pequeña cantidad de drogas), madres solteras. Nuestro argumento es que la perspectiva interseccional permite superar el análisis descriptivo y estanco de los factores involucrados en crímenes cometidos por mujeres y su consecuente encarcelamiento, aclarando cómo el sistema penal puede incorporar y perpetuar formas naturalizadas de control de los cuerpos femeninos y la injusticia social. Concluimos que la mirada interseccional ilumina las complejas situaciones biográficas y vivencias cotidianas de opresión que afectan a cerca de 45 mil mujeres en prisiones brasileñas hoy.

Palabras clave: Encarcelamiento Femenino; Interseccionalidad; Criminología Feminista. 


\section{Introdução}

De acordo com os dados da $4^{\text {a }}$ edição do World Female Imprisonment List (WFIL), divulgado pelo International Centre for Prison Studies (ICPS) (2017), existem mais de 714 mil pessoas do sexo feminino em prisões no mundo, evidenciando-se o crescimento de $53 \%$ da população carcerária feminina em todos os continentes desde 2000. No continente americano, o crescimento na taxa de encarceramento feminino nesse período foi três vezes maior que as taxas de crescimento geral da população do continente. Além disso, a população carcerária feminina mundial tem crescido mais rápido, em termos proporcionais, que a população carcerária masculina.

No Brasil, o número de mulheres em situação de cárcere aumentou aproximadamente $656 \%$ desde o começo do milênio, considerando o número de $42 \mathrm{mil}$ mulheres presas até junho de 2016, segundo dados do Infopen Mulheres $2^{a}$ edição (Brasil, 2018). Os números representam um crescimento na taxa de aprisionamento feminino 4,5 maior que os dados de 2000, segundo o WFIL (ICPS, 2017). Considerando a atualização posterior desses números no fim de 2016, essa população subiu para 44.721 detentas, com um crescimento de aproximadamente $698 \%$ em comparação com o ano de 2000.

A elevação substancial de tais taxas no Brasil, mas também noutros países com diferentes níveis de desenvolvimento - tais como El Salvador, Camboja, Indonésia e Guatemala -, preocupa os responsáveis por políticas públicas em todo o planeta, dado o alto custo financeiro e social do aprisionamento de mulheres. Além de não contribuir para maior segurança pública, o encarceramento feminino em ascensão tem sido reconhecido como excessivo e fonte adicional de vulnerabilidade e vitimização para elas e prejuízo para a sociedade em geral. Neste sentido, cientistas sociais, gestores e profissionais da área jurídica e assistencial vem se perguntando sobre os fatores imbricados nessa realidade e desafiando-se a encontrar formas de saná-los.

Com efeito, o ambiente do cárcere ainda é um espaço prioritariamente masculino em números absolutos (Buglione, 2006) mas, como sugerem os dados acima, há que se investigar a fundo as dimensões estruturais e conjunturais implicadas no atual cenário de criminalização e aprisionamento de mulheres. Do ponto de vista mais amplo, um caminho para entender o problema são as profundas mudan- ças econômicas, políticas e sociais em curso na sociedade global e de matiz dominantemente neoliberal que vem alterando drasticamente o quadro de empobrecimento feminino e levando à seleção perversa de mulheres pelo sistema penal. Concorre ainda para a elevação do número de aprisionadas a adoção de políticas de segurança pública equivocadas, cujo foco é a dura repressão às drogas. A feminização da pobreza e a inserção precária da mulher no mercado de trabalho (Chernicharo, 2014) de fato articulam-se ao tráfico de drogas, um negócio que crescentemente vem recrutando e vitimizando mulheres e meninas, além do já alarmante contingente de homens e meninos.

Ademais, deve-se levar em conta os trâmites dos processos judiciais que frequentemente operam para a reprodução da injustiça social, com base no entrelaçamento da discriminação de gênero, raça-etnia e classe, desde a abordagem policial até o sentenciamento e a reclusão de mulheres. O resultado desse conjunto de fatores é visível no perfil sociodemográfico da população carcerária feminina em ascensão. No contexto brasileiro de guerra às drogas e inchaço do Estado Penal (Wacquant, 1999), o perfil de aprisionadas tem sido principalmente jovens entre 18 a 33 anos, declaradas negras ou pardas, com ensino fundamental incompleto, respondendo por tráfico de drogas (flagradas com pequena quantidade de drogas) e mães solteiras.

No entendimento de tal situação, a criminologia, principalmente em suas linhagens críticas, feministas e com abordagem interseccional, ajuda a compreender os processos opressores de criminalização que levam certas populações a serem tendenciosamente selecionadas pelo sistema penal (Andrade, 1995; Baratta, 1999, 2002; Espinoza, 2004; Mendes, 2014; Zaffaroni, 1993). A categoria gênero, sublinhando a construção social das noções de "mulher" e "homem" e de comportamentos e identidades "femininos" e "masculinos" (Pateman, 1993; Rubin, 1975; Saffioti, 2004; Scott, 1995) dá pistas para compreender porque as mulheres têm sido menos criminalizadas que os homens ao longo da história. O fenômeno deve-se em parte à feminilidade hegemônica que caracteriza a mulher como um ser frágil, passivo, menos afeito à violência e ao cometimento de crimes e frequentemente vítima de agressores do sexo masculino. A teorização sobre o gênero nos estudos criminológicos, na esteira da crítica feminista, também ajuda a compreender as novas dimensões genderizadas do 
aumento do aprisionamento feminino em curso, uma vez que se passa a insistir na interpretação do sistema de justiça criminal como mais uma manifestação do poder patriarcal, que opera numa lógica de controle social sexualizado dos corpos femininos.

Isoladamente, contudo, o gênero considerado como variável é limitado para dar conta deste cenário, uma vez que a seletividade penal no país e noutras partes do mundo não afeta de forma similar mulheres brancas e negras, pobres e ricas. O controle social de tais corpos é também racializado e se entrecruza com outras hierarquias no campo do poder. Como já antecipamos, a maior parte das prisioneiras no país (como ocorre em toda a América Latina) é composta por negras e pardas empobrecidas e com baixa escolaridade.

Dessa forma, buscamos neste artigo apresentar e discutir a criminalização de mulheres, a partir de uma ótica interseccional, realçando a intersecção de gênero, raça-etnia, pobreza e outras fontes de subordinação como central para entender o encarceramento em massa na atualidade, especialmente o feminino, bem como para seu enfrentamento. Nosso argumento é que a perspectiva da interseccionalidade permite superar a análise descritiva e estanque dos fatores envolvidos na prática do crime cometido por mulheres e seu consequente encarceramento, esclarecendo como o sistema judicial pode incorporar e perpetuar a injustiça social. O olhar interseccional, não sendo mero exercício intelectual (Paik, 2016), lança uma luz mais matizada sobre as complexas situações biográficas e as vivências cotidianas de opressão que afetam cerca de 45 mil brasileiras apenadas.

\section{Molduras teórico-metodológicas}

Este trabalho caracteriza-se como um ensaio interpretativo sobre as taxas de encarceramento de mulheres e o perfil sociodemográfico da população carcerária feminina no país e na América Latina, divulgadas em documentos públicos oficiais tais como: Levantamento Nacional de Informações Penitenciárias - Infopen Mulheres (Brasil, 2017; 2018); World Female Imprisonment List (ICPS, 2017), o relatório Sistemas sobrecargados: Leyes de drogas y cárceles en América Latina (Washington Office on Latin America -WOLA, \& Transnational Institute -TNI, 2010), Mujeres en prisión: Los alcances del castigo, publicado pelo Centro de Estudios Legales y Sociales - CELS (Argentina, 2011), bem como os relatórios da Comissão
Econômica para a América Latina e o Caribe (Cepal), La matriz de la desigualdad social en América Latina (2016) e Panorama social da América Latina (2017).

Os dados estatísticos e outras informações selecionados foram analisados e interpretados a partir de princípios da criminologia crítica feminista e do pensamento interseccional. A análise e interpretação desse conjunto de dados foram realizadas à luz de uma literatura crítica nacional e internacional sobre a criminalização e o encarceramento em massa, especialmente de mulheres jovens, negras e pobres, de modo a explicar as condições que levaram ao aumento exponencial da população carcerária feminina no Brasil, bem como as consequências desastrosas da seletividade penal dessas camadas sociais e os desafios que representam para a teorização e a intervenção psicológica nesse cenário.

A interseccionalidade é aqui utilizada enquanto uma ferramenta analítica para entender como diferentes práticas de discriminação se entrecruzam e se perpetuam, oriundas de uma combinatória de desvantagens sociais ligadas a gênero, classe socioeconômica, raça e etnia, sexualidade, idade, capacidades físicas e mentais, ideais de masculinidade e feminilidade entre outras. Em suas origens, o conceito de interseccionalidade tem como fundamento a tradição acadêmica do feminismo negro norte-americano (que inclui pensadoras como Frances M. Beal, Patricia Hill Collins, Angela Davis e Bell Hooks), e a militância de movimentos negros, de mulheres, entre outros (Paik, 2017).

É no fim da década de 1980, porém, que a advogada e feminista negra Crenshaw (1989) introduz e desenvolve o termo, utilizando-o para discutir a interação e superposição de identidades raciais e sexuais subjacentes à discriminação social. Em seu texto "Demarginalizing the intersection of race and sex: a Black feminist critique of antidiscrimination doctrine, feminist theory and antiracist politics", a autora mostra como a formulação e a aplicação das leis tendiam a considerar esses marcadores sociais como isolados ou excludentes. Crenshaw aplicou o conceito ao tratar dos dilemas legais enfrentados por mulheres negras em situações de discriminação no trabalho, que diferiam tanto da discriminação sofrida por homens negros quanto da sofrida por mulheres brancas (Potter, 2013). Tais nuanças da experiência de ser mulher $e$ negra não eram reconhecidas pelos tribunais, cujas decisões tendiam a considerar as queixas 
de discriminação ora por racismo ora por sexismo. $\mathrm{Ou}$ seja, Crenshaw passou a focalizar como certas discriminações "operam juntas", reconhecendo que "as experiências das mulheres negras não podem ser enquadradas separadamente nas categorias da discriminação racial ou da discriminação de gênero." (Crenshaw, 2004, p. 8). Ambas formas de discriminação devem ser consideradas mutuamente, de modo a incluir a questão racial no debate de gênero, e a questão de gênero no debate racial.

Em seu artigo posterior, o clássico "Mapping the margins: intersectionality, identity, politics and violence against women of color", Crenshaw (1991) avança a discussão do conceito, identificando três dimensões articuladas da interseccionalidade estrutural, política e representacional-que explicam a dinâmica e controversa equação entre diferenças e solidariedades quando se trata de lutar contra a opressão e por justiça social (Potter, 2013). Ao trazer casos de violência doméstica e estupro contra mulheres negras nos Estados Unidos, a autora explica que as três dimensões sustentam a discriminação interseccional da qual essas mulheres são vítimas: a estrutural as posiciona nos estratos sociais em maior desvantagem econômica e, consequentemente, em maior risco de sofrer tais formas de violência do que as mulheres brancas; a política se refere à legislação e às políticas públicas que muitas vezes silenciam ou desvalorizam as experiências diferenciadas dessas mulheres, em nome de uma experiência feminina universal ou de uma luta antirracista que exclui a questão do sexismo; por fim, a representacional trata como representações e imagens racistas e sexistas em discursos culturais mais abrangentes marginalizam as mulheres negras (Paik, 2017, p. 5).

$\mathrm{O}$ olhar interseccional aplicado à criminologia vem transformando os rumos da teorização nesta disciplina que emergiu historicamente de uma epistemologia positivista, voltada para estabelecer de modo determinista as relações entre variáveis sociais e comportamento criminal. A lente interseccional permite superar essa orientação, como argumentam De Coster e Heimer (2017), ao enfatizar que os efeitos de desigualdades estruturais não são simplesmente "aditivas", mas interativas e multiplicativas, e ao sublinhar "a construção social de experiências no contexto de desigualdades associadas à raça, classe, gênero, idade e orientação sexual" (p. 12).
A criminologia interseccional pode, então, ser definida como: "uma abordagem teórica que demanda uma reflexão crítica sobre as identidades e status interconectados de indivíduos e grupos em relação às suas experiências criminais, ao controle social do crime e a quaisquer questões associadas ao crime" (Potter, 2013, p. 305). Portanto, é uma perspectiva que permite analisar o impacto das posições sociais interligadas ocupadas pelos indivíduos em relação ao crime, seja na condição de agressores ou de vítimas. A perspectiva tem sido amplamente defendida para sua aplicação e fortalecimento em pesquisas criminológicas (Belknap, 2015; Bell, 2017; Daly, 2006).

Em estudos que envolvem temáticas criminais, a perspectiva interseccional vem deixando de ser uma simples aspiração, como se queixava Daly (2006), para ser cada vez mais incorporada por pesquisadoras feministas, sempre buscando atentar como múltiplas formas de subalternidade pavimentam a trajetória de certos segmentos da população feminina rumo as prisões e também dentro das prisões. No Brasil, a abordagem crítica, feminista e interseccional está associada, direta ou indiretamente, aos trabalhos acadêmicos e ativistas que denunciam a seletividade penal de mulheres e sua experiência de opressão, entre esses os trabalhos de Borges (2018), Flausina (2008), Pires (2013), Silveira e Nardi (2014), Carvalho e Mayorga, 2017, e outros. Tais estudos obviamente também pressupõem a larga contribuição da militância feminista negra de Lélia González (1935-1994), Luiza Bairros (1953-2016), Sueli Carneiro (1950-), Vilma Reis (1969-) entre tantas outras.

Como defendem Owen, Wells e Pollock (2017), o paradigma interseccional

desvenda a experiência de mulheres na prisão na medida em que focaliza os efeitos multiplicativos destas identidades, superando a definição monolítica de gênero. Com as diferenças reais nas vidas de mulheres sendo mediadas pela posição social, o status subordinado adicional de "prisioneira", "interna", "condenada" acrescenta outra camada às opressões e à marginalidade das mulheres enquanto elas cumprem suas sentenças (p. 7).

Neste sentido, destacamos em seguida alguns dados sobre as atuais taxas e condições de encarceramento feminino no Brasil que exigem uma interpretação crítica informada pelos feminismos e pela pers- 
pectiva interseccional, além de uma mudança nos métodos de investigação do problema e de atuação profissional nesse campo.

\section{Resultados e discussão}

\section{0 crescimento da criminalidade e encarceramento feminino e as perspectivas criminológicas}

Como a Figura 1 assinala, pode-se observar o aumento expressivo da taxa de aprisionamento feminino de 2000 a 2016, quando se culmina com mais de 40 mulheres presas para cada 100 mil mulheres, utilizando-se critérios de cálculo populacional adotados internacionalmente para fins comparativos (Brasil, 2018). Se excluirmos desse cálculo a população de meninas e adolescentes do sexo feminino abaixo de 18 anos (população inimputável no país), essa taxa sobe ainda mais.

Considerando a problemática do aumento exponencial do encarceramento da população feminina no Brasil e alhures, perguntamos: como a criminologia feminista, crítica e interseccional pode lançar luz sobre esse fenômeno? Como pode ajudar a compreender a recente escalada do aprisionamento feminino nas últimas décadas, que vem superando as taxas de encarceramento masculino no país?

Certas abordagens biológicas na criminologia forneceram explicações para os índices mais baixos de mulheres em comportamento delinquente, recorrendo a diferenças sexuais naturais e universais entre os sexos. Em oposição, o pensamento feminista sublinha a necessidade de entender sob o viés de gênero o comportamento de homens e mulheres agressores e vítimas e sugere que a desproporção das estatísticas entre as duas populações é "produto das diferenças de gênero mais do que das diferenças de sexo" (Portella, 2014, p. 160).

Contudo, a posição secundária ocupada pela mulher no sistema punitivo, com seu baixo número absoluto de encarceramento, se comparado ao masculino, leva à errônea compreensão de que mulheres são menos selecionadas pelo sistema penal em razão do fato de cometer menos crimes. Por essa linha de pensamento, tende-se a pensar que o sistema punitivo está restrito à criminalização e ao aprisionamento, quando sua gênese e força estão no poder de vigilância como aparato de controle social. Desta forma, mesmo com o debate paradigmático intenso no campo, os estudos acerca da criminalidade feminina consideraram por muito tempo que a seletividade penal tinha gênero e este era primariamente masculino (Zaffaroni, 1993). Porém, com o aumento da taxa de criminalidade feminina no país nas duas últimas décadas, passou-se a reconhecer que a inserção feminina no âmbito criminal responde a certos critérios de seletividade penal que se aproximam dos masculinos.

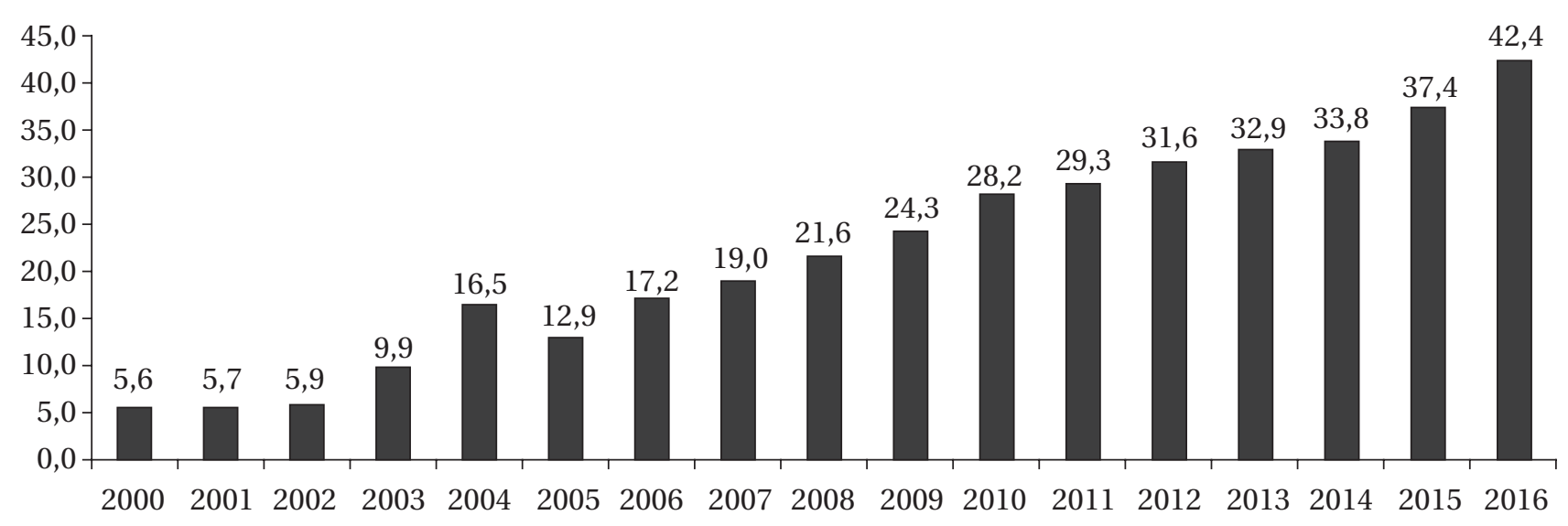

Fonte: “Levantamento Nacional de Informações Penitenciárias - Infopen Mulheres, 2a edição” de Brasil (2018). Brasília-DF, Ministério da Justiça e Segurança Pública; Departamento Penitenciário Nacional-DEPEN; p. 10. Recuperado de: http://depen. gov.br/DEPEN/depen/sisdepen/infopen-mulheres/infopenmulheres_arte_07-03-18.pdf.

Figura 1

Evolução da população de mulheres no sistema penitenciário brasileiro. Brasil, 2000 a 2016. 
Focalizar o entrelaçamento entre o sistema patriarcal capitalista e racista ajuda a compreender como os mecanismos de opressão e marcadores sociais de seletividade do sistema penal se repetem em relação à seleção das mulheres presas. Esses sistemas de opressões estão inseridos num contexto de implementação de políticas neoliberais, de forma que as mulheres encontram-se duplamente dominadas e exploradas (Silva, 2017). Esse padrão de seletividade penal por classe social e cor acaba por discriminar um certo perfil de mulher que é encarcerada.

O perfil da mulher presa reforça o já conhecido perfil dos presos em geral, representando a situação de vulnerabilidade social e econômica em que se encontram as mulheres alvo da seletividade penal. De acordo com Del Olmo (1996), as mulheres veem no crime, especialmente no tráfico de drogas e entorpecentes, uma oportunidade de ascensão social, de complementar a renda e de estar presente em casa na criação dos filhos. Assim, a pequena atividade varejista no tráfico de drogas, que lhes permite trabalhar sem se ausentarem por longos períodos do lar, acaba por representar uma ocasião de continuarem desempenhando os papéis sociais tradicionais de cuidado dos filhos.

No âmbito da criminologia como disciplina, a criminalidade feminina tem sido abordada segundo diferentes paradigmas que sustentam por sua vez diferentes correntes teóricas: o paradigma etiológico subjacente à criminologia positivista, o paradigma da reação social que apoia a criminologia crítica e, mais recentemente, o paradigma de gênero que norteia a criminologia feminista (Andrade, 1995; Baratta, 2002; Espinoza, 2004; Mendes, 2014).

A criminologia positivista, tributária dos pressupostos epistemológicos dominantes no século XIX, e concebendo-se como ciência causal-explicativa, tendia a abordar a criminalidade como um fenômeno determinado por causas naturais. De acordo com Andrade (1995), o paradigma etiológico dá sustentação para a tese de que ser criminoso é uma propriedade individual que distingue os sujeitos delinquentes dos indivíduos ditos "normais". O grau de periculosidade considerado anormal seria a justificativa da pena, entendida como defesa da sociedade.

A criminologia crítica surge na década de 1960 como um contraponto ao determinismo biológico definido pelo paradigma etiológico, operando um deslocamento no objeto da disciplina. Deixa-se de focar no indivíduo criminoso e nas causas da criminalidade e volta-se para o processo de criminalização de determinados sujeitos e na criminalidade enquanto reação a condições sociais (Andrade, 1995). O sistema penal é entendido como um sistema de direito desigual para a manutenção do poder da classe dominante através da criminalização da classe subalterna (Baratta, 2002).

Embora a ascensão do movimento feminista seja contemporânea à criminologia crítica, apenas na década de 1980 foi possível observar seu legado no debate paradigmático da disciplina. Segundo Mendes (2014), a inserção dos estudos de gênero no campo da criminologia levou estudiosos a interpretar a lógica e a práxis do sistema de justiça criminal como expressão do poder patriarcal, portanto a seu serviço.

De acordo com Baratta (1999), é a partir da consolidação da criminologia crítica, atrelada ao paradigma de gênero, que se torna possível compreender a posição da mulher no sistema jurídico e prisional, seja como vítima ou como autora do delito. Os estudos em criminologia feminista efetuaram um giro epistemológico, inovando a concepção da criminalidade feminina, ao denunciar o caráter androcêntrico das ciências criminológicas e seu silêncio em torno da mulher autora de atos criminais. A criminologia feminista vem contestando o sexismo das teorias sobre a criminalidade feminina que ainda reforçam estereótipos sobre a inferioridade biológica da mulher e que servem para manter o status quo, seja na vertente clássica (positivista) ou crítica (Espinoza, 2004; Mendes, 2014). Munido de ferramentas interseccionais, $o$ estudo da criminalização feminina na esfera do paradigma de gênero vem abordando a opressão multifatorial e articulada sofrida pelas mulheres no contexto global de dominação patriarcal, capitalista e racista.

No que diz respeito ao encarceramento feminino no Brasil, além de entender os marcadores sociais em interação que produzem o crescimento expressivo da taxa, faz-se necessário compreender também os processos históricos de punição de mulheres e homens em diferentes estratos sociais ao longo do processo civilizatório. Mulheres rebeldes e agressivas, contrariando a imagem consagrada de passividade feminina, tem sofrido segregação social e estigmatização como "loucas", diferente do que ocorre aos homens, punidos como fora da lei e criminosos. O discurso sobre a criminalidade reproduzido pelas instituições que a controlam construiu-se com base na distinção do "criminoso" e do "insano", e, dessa forma, o gênero 
configurou-se um elemento importante de estruturação das políticas penais (Zaffaroni, 1993).

Voltando-se para a interação de formas de subordinação, Davis (2003) atenta também para as disparidades da punição das mulheres enquanto loucas e criminosas ao longo da história. Raça e classe social infelizmente ainda atuam como fatores diferenciadores para se rotular uma mulher de "louca" e "criminosa": a loucura tende a ser atribuída às mulheres brancas e de classes socioeconômicas mais altas, enquanto as mulheres negras são enquadradas como criminosas. Nesse sentido, é particularmente importante que os profissionais do campo da saúde mental no sistema prisional, mas também nos contextos de proteção preventiva, desenvolvam maior sensibilidade para a singularidade das experiências femininas como agressoras e vítimas, antes e depois de apenadas, bem como uma formação mais robusta que lhes permita enfrentar a interconexão de desvantagens sociais do seu público-alvo.

\section{Feminização da pobreza, política de guerra às drogas e seletividade penal: $o$ perfil sócio-demográfico das presidiárias no Brasil e na América Latina}

No que tange à faixa etária das presidiárias, $27 \%$ tem entre 18 e 24 anos e $23 \%$ entre 25 e 29 anos, portanto, as mulheres jovens representam a metade da população das encarceradas, segundo dados do Infopen Mulheres (Brasil, 2018). Contudo, como mostram as Figuras 2 e 3 abaixo, o recorte racial de seletividade penal das mulheres é ainda mais revelador: em torno de $62 \%$ se declaram negras, em contraste com pessoas que se declaram brancas (37\%).

A baixa escolaridade também é uma marca do encarceramento feminino no país; aproximadamente $66 \%$ não alcançou o ensino médio, tendo no máximo ensino fundamental incompleto. $\mathrm{O}$ ensino médio completo é declarado por apenas $15 \%$ das presidiárias, segundo o Infopen Mulheres (Brasil, 2018). O conjunto dos dados revela o cenário de exclusão escolar subjacente à redução de oportunidades formativas e laborais antes do aprisionamento e que permanece durante o cumprimento da pena, considerando as condições precárias gerais das unidades prisionais também nessa seara.

Em contexto macroestrutural, o cenário de encarceramento em massa de mulheres em todo o planeta resulta de um conjunto de processos em curso desde a década de 1970: a ascensão de políticas neoliberais reduzindo o Estado Social (Wacquant, 1999), a consolidação da política global de guerra às drogas e endurecimento das penas (Boiteux, 2006a, 2010, 2015; Chernicharo, 2014; Del Olmo, 1998; Moura, 2005), a feminização da pobreza e o crescente empobrecimento de lares chefiados unicamente por mulhe-

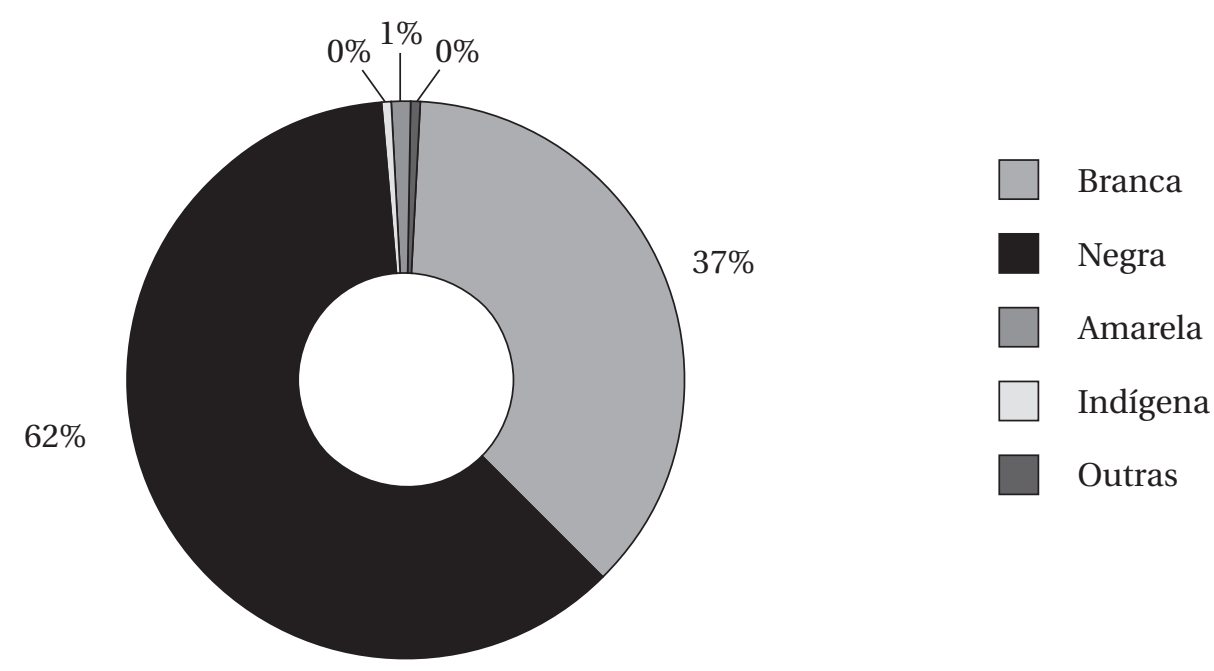

Fonte: “Levantamento Nacional de Informações Penitenciárias- Infopen Mulheres, 2a edição” de Brasil (2018). BrasíliaDF, Ministério da Justiça e Segurança Pública; Departamento Penitenciário Nacional-DEPEN. p. 40. Recuperado de http://depen.gov.br/DEPEN/depen/sisdepen/infopen-mulheres/infopenmulheres_arte_07-03-18.pdf.

Figura 2

Raça, cor ou etnia das mulheres privadas de liberdade. 


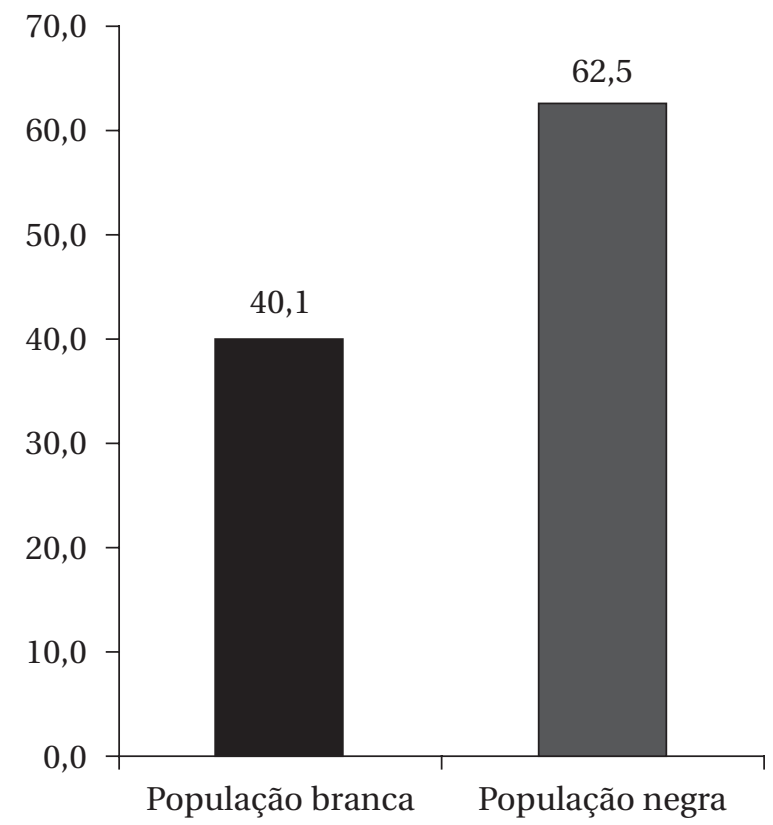

Fonte: "Levantamento Nacional de Informações Penitenciárias - Infopen Mulheres, $2^{\mathrm{a}}$ edição” de Brasil (2018). Brasília-DF, Ministério da Justiça e Segurança Pública; Departamento Penitenciário Nacional-DEPEN. p. 41. Recuperado de http://depen.gov.br/DEPEN/depen/sisdepen/ infopen-mulheres/infopenmulheres_arte_07-03-18.pdf.

Figura 3

Taxa de aprisionamento por 100 mil mulheres maiores de 18 anos da população branca e negra no Brasil.

res (Costa, Pinheiro, Medeiros, \& Queiroz, 2005), e o fenômeno geral da criminalização da pobreza, que fomenta a penalização das camadas pobres das populações (Wacquant, 1999).

A feminização da pobreza, termo cunhado pela socióloga norte-americana Diane Pearce e utilizado pela primeira vez em 1978, diz respeito ao processo histórico de aumento da proporção de mulheres entre os pobres nos Estados Unidos da América e à expansão do número de famílias em condições de vulnerabilidade socioeconômica que são chefiadas por mulheres. Posteriormente o termo foi utilizado como ferramenta para pesquisas do problema noutros países (Costa et al., 2005). Na interface entre desvantagem socioeconômica e de gênero, o problema está associado às condições laborais desiguais das mulheres, envolvendo atividades precarizadas, irregulares e mal remuneradas, além da responsabilidade por atividades domésticas e maternas (Chernicharo, 2014).

Esse é um fenômeno que tem aumentado na América Latina, de modo que a pobreza é atravessada por fatores relacionados com a localização territorial, e, principalmente, com o gênero e a raça, como visto no documento La matriz de la desigualdad sócial en América Latina (2016), elaborado pela Cepal. Essas dimensões se cruzam, revelando a face interseccional da pobreza na América Latina. O maior número de pessoas desempregadas é composto por mulheres e os dados indicam a dimensão de raça/etnia, de gênero e de faixa etária do desemprego feminino (CEPAL, 2016).

A menor participação econômica das mulheres devido à distribuição sexual do trabalho e às crises econômicas constituem barreiras para a emancipação e autonomia feminina, sendo uma das causas de sua maior vulnerabilidade como mostra o relatório Panorama social da América Latina (CEPAL, 2017). As mulheres têm tido dificuldades em se inserir no mercado de trabalho formal, o que acaba por resultar na sua inclusão precária em atividades informais e em múltiplas jornadas de trabalho.

A fragilização de políticas sociais, especialmente a partir da década de 1990, intensificou a vulnerabilidade feminina. Enquanto o Estado torna-se cada vez menos regulador da esfera socioeconômica, fortalece-se o Estado penal, cada vez mais reforçador do aparelho punitivo estatal e mais tendente a criminalizar os pobres (Wacquant, 1999).

Nesse cenário também ocorreu a adoção de políticas de guerra às drogas, por influência norte-americana. Esse sistema conjecturava a elaboração de uma política proibicionista internacional de drogas, em que objetivo a ser alcançado seria a erradicação do consumo e do tráfico através de políticas punitivistas (Boiteaux, 2006a). A política antidrogas vem influenciando decisivamente o funcionamento do sistema penitenciário latino-americano. Os países da América Latina adotaram medidas proibicionistas em detrimento de políticas preventivas, enfatizando a privação de liberdade como medida de repressão ao controle de drogas, o que ocasionou o aumento exponencial do número de homens e mulheres encarcerados (Argentina, 2011; Giacomello, 2013).

A legislação adotada pelos países latino-americanos, apesar de distintas, apresentam semelhanças entre si, de modo que há fatores que implicam no aumento da população carcerária (Chernicharo, 2014). Neste contexto, os critérios restritivos de garantias individuais atrelados à imposição do encarceramento preventivo são os antecedentes do aumento da população carcerária feminina (Argentina, 2011, p. 24). 
Essas políticas contribuíram significativamente para o boom exponencial da população carcerária na América Latina a partir da década de 1990. Das razões que propiciaram o aumento do encarceramento de mulheres no Brasil, a Lei de Drogas de no 11.343/2006 é considerada um fator relevante. A lei foi lançada visando proteger o bem jurídico da saúde pública e teve como objetivo despenalizar o usuário, enrijecer as penas para o traficante e criar o Sistema Nacional de Políticas Públicas sobre Drogas (SISNAD).

De acordo com Boiteux (2006b, 2010, 2015, 2017), inicialmente, a nova lei de drogas foi considerada uma lei progressista no que diz respeito à despenalização de usuários de substâncias ilícitas, pois reflete a redução do controle penal sobre o usuário. Porém, é considerada regressiva no que tange à comercialização, visto que a pena mínima para posse de substâncias ilícitas aumentou e que essa lei intensificou ainda mais o estigma de usuário e traficante e o abismo de tratamento existente entre ambos.

A Lei $\mathrm{n}^{\circ} 11.343 / 06$ carece de informações concretas e legais que diferenciem o traficante do usuário, de modo que a apreensão se dá pelo julgamento subjetivo de quem atua no momento da abordagem e de quem julga posteriormente, como explicita a lei em seu artigo 28, §2:

Para determinar se a droga destinava-se a consumo pessoal, o juiz atenderá à natureza e à quantidade da substância apreendida, ao local e às condições em que se desenvolveu a ação, às circunstâncias sociais e pessoais, bem como à conduta e aos antecedentes do agente.

Baseado nos preceitos da criminologia crítica e feminista, entende-se que são certos indivíduos pertencentes às classes subalternas que são previamente criminalizados e selecionados pelo sistema penal. Assim, sabe-se que, por falta de critérios objetivos para identificação de um usuário ou traficante, como a quantidade específica para ser considerada consumo ou tráfico, arrisca-se a interpretar, de forma subjetiva e preconceituosa, a identidade e conduta do(a) suspeito(a) com base em informações tais como local da apreensão, cor da pele, aparência e estilo de vida da pessoa abordada, entre outros aspectos. Esse é um dos modos em que se efetiva a autuação de pessoas negras, pobres e jovens enquanto traficantes, como já apontam as estatísticas.
O endurecimento das penas, a equiparação de tráfico ao crime hediondo, a falta de objetividade em distinguir o usuário do traficante, a permanência de presos provisórios sem condenações no sistema foram os principais fatores responsáveis pelo acelerado crescimento da população carcerária no Brasil (Boiteaux, 2015). Assim, apesar do debate que se faz sobre as políticas de drogas e o proibicionismo no Brasil, a superlotação das prisões e as condições penitenciárias pioraram consideravelmente sob a influência direta dessas políticas.

De acordo com os estudos feitos pelo CELS (Argentina, 2011) e pelo WOLA e TNI (2010), que produziram respectivamente, os documentos Mujeres en prisión: Los alcances del castigo (2011) e Sistemas sobrecargados - Leyes de drogas y cárceles en América Latina (2010), constatou-se que o motivo principal do aprisionamento de mulheres por crimes de drogas na América Latina se deu pelo transporte de pequenas quantidades de drogas, numa atividade em que recebem o nome de "mulas". Com efeito, cerca de $64 \%$ das mulheres presas em penitenciárias latino-americanas estão detidas em decorrência de crimes de drogas (Giacomello, 2013), sendo este percentual maior que o de homens em todos os países da América Latina. A figura 4 abaixo revela que esses números se aproximam do cenário brasileiro, onde o tráfico de drogas é o tipo de crime que tem mais privado as mulheres de liberdade.

Essas atividades de transportação de drogas são de maior exposição e representam maior risco de apreensão pelo sistema punitivo, de modo que essas mulheres têm sido mais selecionadas pelo sistema penal. Nos dois estudos (Argentina, 2011; WOLA/TNI, 2010), as atividades de narcotráfico aparecem como uma alternativa econômica motivada pela vulnerabilidade socioeconômica em que essas mulheres se encontram. Assim, há a feminização dos delitos de tráfico de drogas.

O aumento expressivo da população carcerária feminina por crimes relacionados às drogas é uma tendência mundial e suas consequências são sentidas, principalmente, por mulheres dos países latino-americanos.

\section{Riscos e danos à segurança e bem-estar das mulheres encarceradas no Brasil}

Para entender o quadro de saúde, segurança e bem-estar das mulheres em estabelecimentos prisionais no Brasil, deve-se considerar a história do 


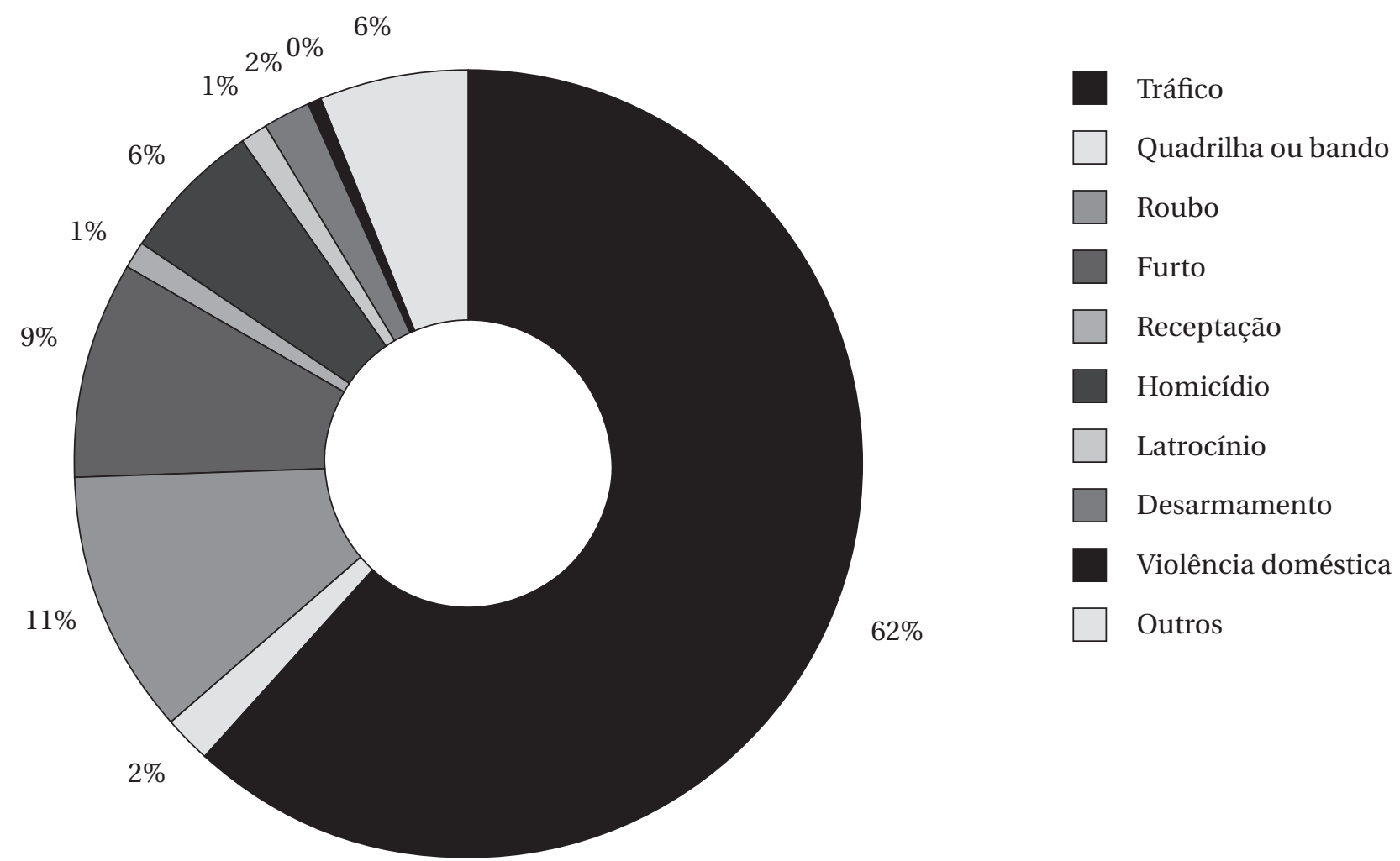

Fonte: “Levantamento Nacional de Informações Penitenciárias - Infopen Mulheres, 2a edição” de Brasil (2018). Brasília-DF, Ministério da Justiça e Segurança Pública; Departamento Penitenciário Nacional - DEPEN. p. 54. Recuperado de http://depen. gov.br/DEPEN/depen/sisdepen/infopen-mulheres/infopenmulheres_arte_07-03-18.pdf.

Figura 4

Distribuição dos crimes tentados/consumados entre os registros das mulheres privadas de liberdade, por tipo penal no Brasil.

encarceramento feminino no país e suas especificidades em relação ao encarceramento masculino. De acordo com Queiroz (2015), o primeiro presídio brasileiro destinado ao público feminino funcionava como um dispositivo moralizante e recebia as mulheres vistas como desviantes, ou seja, as mães solteiras, prostitutas, bem como aquelas ditas "de gênio forte", que se recusavam a obedecer às ordens que lhe eram impostas.

Esta primeira penitenciária, construída em Porto Alegre (RS), em 1937, foi fundada por freiras da Igreja Católica e não pelo Estado. A intenção era retirar as mulheres que, à época, cumpriam suas condenações em cadeias mistas e, por conta disso, sofriam uma série de violações e violências. Todavia, tal instituição findou por tornar-se, efetivamente, um depósito de mulheres "desajustadas" (não necessariamente criminosas), que, de algum modo, fugiam do padrão da sociedade patriarcal e machista.
Com efeito, o entendimento crítico da experiência de encarceramento de mulheres exige a compreensão da gênese histórica das prisões, das singularidades de gênero envolvidas e dos seus aspectos estruturais, conjunturais e ideológicos. Esse olhar abrangente remonta a discussões fundamentais, como as de Goffman (2010) e Foucault (1975/1987), a respeito das instituições totais e sua lógica de disciplinamento, domesticação, normatização e despersonalização, levando-nos a refletir acerca da própria existência dos presídios e da seletividade penal que os multiplicam.

Como assinala Diniz (2015), “[...] o presídio é uma máquina de abandono para a qual os sentidos da violência são múltiplos” (p. 210). No caso das mulheres, essas violências ganham materialidades variadas, das mais explícitas (como, por exemplo, mulheres que foram obrigadas a parir algemadas) às menos óbvias, encontradas, por exemplo, na arquitetura prisional 
(onde há dependências sem creche e o vaso sanitário é substituído por um buraco no chão) e no acesso restrito a produtos de higiene feminina (levando muitas a usarem miolo de pão como absorventes).

O cenário concreto é de celas superlotadas, insalubres e sem conforto, acesso precário ou ausente a tratamentos médicos e a serviços especializados em saúde da mulher, más condições de higiene, pobreza e dificuldade de acesso a bens necessários, exposição aumentada a conflito e violência entre internas e entre internas e equipe, baixa escolaridade, limitação em oportunidades educacionais e laborais.

O quadro é de franca violação às Regras de Bangkok, isto é, às Regras das Nações Unidas para o tratamento de mulheres presas e medidas não privativas de liberdade para mulheres infratoras, de 2010. Reconhecendo o viés androcêntrico do sistema prisional, as Regras de Bangkok visam garantir que necessidades e direitos específicos de mulheres custodiadas sejam atendidos desde o seu ingresso no sistema, o que abrange normas de ingresso, alocação, atendimento médico e cuidados à saúde física e mental, de revista, contenção, visitas, entre outras. Preveem também formas de flexibilização do regime e outras medidas que buscam também proteger seus filhos e sua família e favorecer a readaptação às suas comunidades após o encarceramento. O Conselho Nacional de Justiça (CNJ) reconhece que as Regras de Bangkok "não foram plasmadas em políticas públicas consistentes, em nosso país, sinalizando, ainda, o quanto carece de fomento a implementação e a internalização eficaz pelo Brasil das normas de direito internacional dos direitos humanos囚 (Brasil, 2016, p. 10).

Em seu Presos que menstruam, Queiroz (2015) revela concretamente os sofrimentos de mulheres que passaram pelo cárcere e que resultam da interação entre experiências de subalternidade e opressão antes, durante e depois do aprisionamento. As narrativas comoventes das entrevistadas exibem uma trajetória biográfica anterior ao encarceramento marcada pela escassez material, insegurança, negação de oportunidades educacionais, exploração no trabalho, além de episódios de violência física e emocional, abuso sexual e vulnerabilidade geral. As experiências de opressão e de tratamento indigno recrudescem quando se tornam presas, muitas vezes incitando o conflito e a violência como forma de sobrevivência, com clara ameaça à segurança e à saúde da mulher nesses contextos. A luta pela garantia dos direitos básicos e pela dignidade permanecem centrais nas prisões brasileiras.

Os riscos e prejuízos para a segurança e o conforto das mulheres nas prisões também requerem um olhar crítico, feminista e interseccional. Segundo Owen et al. (2017), os sofrimentos das presidiárias refletem "as desvantagens múltiplas e cumulativas que condicionam seus caminhos rumo à prisão e continuam a moldar suas escolhas e oportunidades na instituição total que é a prisão" (p. 1). Neste sentido, o enquadramento interseccional dessas experiências leva a deslocar o foco de explicações criminológicas centradas em características e patologias individuais para dirigir a atenção para as consequências das iniquidades estruturais na vida das prisioneiras.

A saúde mental aparece como um tema central em relação às pessoas que se encontram em situação de privação de liberdade e, no caso de mulheres, esse contexto pode se tornar especialmente adoecedor, considerando que todo o sistema penal foi criado a partir de uma perspectiva androcêntrica.

Como lembram Rotelli, De Leonardis e Mauri (2001), não é possível separar o sofrimento psíquico da existência global complexa e concreta dos sujeitos e do corpo social. Trata-se, pois, não de pensar uma reificação do adoecimento psíquico, como um ente apartado das condições nas quais ganha materialidade, mas de compreender como as relações sociais, políticas, econômicas, culturais e subjetivas conectam-se, também, nesse processo. Dessa maneira, para o campo dos estudos em saúde mental, a questão de gênero também aparece como um grande desafio. É preciso estimular os estudos, pesquisas e publicações que articulem a questão das mulheres encarceradas e a saúde mental. Há, ainda, uma certa invisibilidade desse sofrimento e de suas especificidades.

Maluf (2014) chama nossa atenção para o fato de que a política pública de saúde tanto pode contribuir para "um regime de diferenciação e reprodução da diferença, quanto pode constituir-se em mais um aparato a interpelar mulheres e homens no sentido da sujeição aos regimes da diferença" (p. 7). Assim, refletir acerca das políticas públicas direcionadas às mulheres encarceradas é uma tarefa necessária e urgente. A pergunta para estudiosos, profissionais e gestores públicos é: como criar mecanismos para combater os fracassos das atuais políticas? Como enfrentar as questões de interseccionalidade encarnadas nesse desafio? 


\section{Considerações finais}

Ao se estudar os fatores que levaram ao aumento da população carcerária feminina em todo o mundo e, em especial, no Brasil, abrem-se também possibilidades de formular práticas de proteção de viés social e políticas públicas específicas para essa população. Os dados aqui discutidos corroboram a teoria da criminologia crítica e feminista sobre as mulheres que são selecionadas e afetadas pelo sistema punitivo. Assim, buscamos responder como a interseção de gênero, raça e classe acomete sobremaneira as mulheres no cárcere, violando seus direitos e reproduzindo formas de discriminação institucionalizadas.

A teorização e a ação profissional com segmentos femininos nos presídios não podem negligenciar o espaço determinado historicamente à mulher em uma sociedade patriarcal e racista. Patriarcado, androcentrismo e discriminação racial aliados à feminização da pobreza, declínio de políticas sociais e um Estado centrado mais na penalização do que na garantia dos direitos convertem-se em prisões cada dia mais lotadas de presas. Além de claramente injusto, esse quadro representa enorme ônus para toda a sociedade.

A perspectiva feminista, incorporada em linhagens críticas da criminologia, alerta que o problema do encarceramento feminino também compromete, além da vida da presidiária, suas famílias e gerações de brasileiros. Sobretudo, o tráfico de drogas, por não exigir qualificação profissional, acaba como uma "opção" de complementação da renda familiar e de cuidados da casa e dos filhos para as camadas mais vulneráveis da população feminina. Por ocuparem posições secundárias na rede do tráfico, as mulheres tornam-se também mais vulneráveis a serem detidas e sentenciadas. Frequentemente as mulheres acabam sendo presas preventivamente, recebem penas consideráveis e tem dificuldades em conseguir a flexibilização do regime devido à rigidez da Lei de Drogas. $O$ entendimento que as mulheres presas são em sua maioria mães e que são as principais responsáveis pela criação dos filhos nos esclarece que não só as mulheres presas são atingidas pelo encarceramento em massa, mas também seus filhos.

É nesse sentido que argumentamos a favor da formulação e implementação urgente de políticas públicas que foquem nas condições específicas das mulheres, no âmbito dos direitos sexuais e reprodutivos, dos direitos das juventudes, da proteção contra os crimes de gênero, da educação, do trabalho e renda, entre outros. Em especial, faz-se necessário um debate profundo com toda a sociedade sobre as políticas de segurança pública vigentes e seu foco na guerra às drogas, desvelando seus fracassos e incitando à criação de novas concepções e alternativas para lidar com o problema. O norte é a mudança nas leis que regem o combate ao crime de tráfico de drogas, de modo a reduzir a discriminação racial-étnica e de classe vigente no atual exercício da Lei de Drogas.

Vale ainda lembrar que, a rigor, as prisões em sua gênese surgiram com o intuito de conter e excluir, como estratégia de controle social, os estratos sociais subordinados e indesejáveis. Por mais que os tratados internacionais, bem como as leis e políticas nacionais operem no sentido da humanização prisional e monitoramento dos direitos humanos nesses espaços, ainda resta uma questão perturbadora: garantir a dignidade das mulheres em sua passagem por estabelecimentos prisionais resolveria o problema? Cremos que não. No horizonte, devemos lutar para que as prisões sejam abolidas e que não mais sejam necessárias. Aqui, menos é mais: menos prisões, mais equidade e justiça social.

Além disso, no que se refere ao campo das psicologias, faz-se necessário fomentar discussões que ultrapassem a mera perspectiva da avaliação e diagnóstico e elaboração de laudos e pareceres sobre a periculosidade da pessoa presa e a possibilidade de ressocialização ou reincidência. $\mathrm{O}$ aspecto controverso da realização de exames e pareceres técnicos por psicólogos no sistema prisional já foi discutido, com a denúncia de seu incômodo mas importante papel "na operacionalização da máquina carcerária em seus dispositivos de sujeição e controle dos presos pelo sistema penal" (Reishoffer, \& Bicalho, 2017, p. 42).

Sem entrarmos na discussão e crítica mais aprofundada a esse respeito, vale, todavia, o questionamento acerca do que está sendo produzido pela Psicologia ao limitar sua atuação a essa função e a qual encargo ou demanda social se está a responder sob essa perspectiva. Entendemos que a Psicologia deve ter uma posição ética e política voltada para a defesa dos direitos humanos e para a construção de possibilidades de saúde (aqui entendida de modo mais amplo, não como ausência de doença). Desse modo, devemos colocar em pauta a função do psicólogo no sistema prisional para que não sejamos apenas uma peça dentro de um sistema excludente, adoecido e adoecedor. 
A Psicologia é convocada a assumir outros lugares, para além de "azeitar a máquina". É urgente e necessário inventar possibilidades de resistência aos efeitos funestos do encarceramento, que afeta a todos, ainda que em proporções e sentidos distintos. É preciso ocupar espaços macro e micropolíticos de atuação que possibilitem uma reflexão ética radical acerca do modelo de sociedade punitivista que estamos ajudando a manter.

\section{Referências}

Andrade, V. R. P. (1995). Do paradigma etiológico ao paradigma da reação social: Mudança e permanência de paradigmas criminológicos na ciência e no senso comum. Sequência, 16(30), 24-36. https://doi.org/10.5007/\%25x

Argentina. (2011). Centro de Estudios Legales y Sociales, Ministerio Público de la Defensa de la Nación, \& Procuración Penitenciaria de la Nación. Mujeres en prisión: Los alcances del castigo. Buenos Aires: Siglo Veintiuno.

Baratta, A. (1999). O paradigma de gênero: Da questão criminal à questão humana. In: C. H. Campos (Org.), Criminologia e feminismo (pp. 19-81). Porto Alegre, RS: Sulina.

Baratta, A. (2002). Criminologia crítica e crítica do direito penal: Introdução à sociologia do direito penal (3a ed). Rio de Janeiro, RJ: Reva.

Belknap, J. (2015). Activist criminology: Criminologists' responsibility to advocate for social and legal justice. Criminology, 53(1), 1-22. https://doi.org/10.1111/1745-9125.12063

Bell, K. E. (2017). Prison violence and the intersectionality of race/ethnicity and gender. Criminology, Criminal Justice, Law \& Society. 18(1), 106-121.

Boiteux, L. (2006a). O controle penal sobre as drogas ilícitas: O impacto do proibicionismo sobre o sistema penal e a sociedade (Tese de doutorado). Faculdade de Direito, Universidade de São Paulo, São Paulo, SP, Brasil.

Boiteux, L. (2006b). A nova lei antidrogas e o aumento da pena do delito de tráfico de entorpecentes. Boletim do Instituto Brasileiro de Ciências Criminais, 14(167), 8-9.

Boiteux, L. (2010). Drogas y prisión: La represión contra las drogas y el aumento de la población penitenciaria en Brasil. In: Washington Office on Latin America - WOLA (Org.), Sistemas sobrecargados: Leyes de drogas y cárceles en América Latina (pp. 30-38). Washington, DC: WOLA.

Boiteux, L. (2015). El antimodelo brasileño: Prohibicionismo, encarcelamiento y selectividad penal frente al tráfico de drogas. Nueva Sociedad, (255), 132-144.

Boiteux, L. (2017). Brasil: Las cárceles de la droga y de la miséria. Nueva Sociedad, (268), 14-22.

Borges, J. (2018). O que é encarceamento em massa? Belo Horizonte, MG: Letramento/ Justificando.

Brasil. (2016). Conselho Nacional de Justiça - CNJ. Regras de Bangkok: Regras das nações unidas para o tratamento de mulheres presas e medidas não privativas de liberdade para mulheres infratoras (Série Tratados Internacionias de Direitos Humanos). Brasília, DF: o autor.

Brasil. (2017). Ministério da Justiça e Segurança Pública. Levantamento Nacional de Informações Penitenciárias (Infopen, atualização junho 2016). Brasília, DF: Departamento Penitenciário Nacional.

Brasil. (2018). Ministério da Justiça e Segurança Pública. Levantamento Nacional de Informações Penitenciárias (Infopen Mulheres, $2^{\mathrm{a}}$ ed.). Brasília, DF: Departamento Penitenciário Nacional.

Buglione, S. (2006). O dividir da execução penal: Olhando mulheres, olhando diferenças. In: S. Carvalho (Org.), Crítica à execução penal (2a ed., pp. 139-158). Rio de Janeiro, RJ: Lumen Juris.

Carvalho, D. T. P., \& Mayorga, C. (2017). Contribuições feministas para os estudos acerca do aprisionamento de mulheres. Estudos Feministas, 25(1), 99-116. https://doi.org/10.1590/1806-9584.2017v25n1p99

Chernicharo, L. P. (2014). Sobre mulheres e prisões: Seletividade de gênero e crime de tráfico de drogas no Brasil (dissertação de mestrado). Centro de Ciências Jurídicas e Econômicas, Universidade Federal do Rio de Janeiro, Rio de Janeiro, RJ, Brasil.

Chernicharo, L. P., \& Boiteux, L. (2014). Encarceramento Feminino, Seletividade Penal e Tráfico de Drogas em uma perspectiva feminista crítica. In: Seminário Nacional de Estudos Prisionais, Marília, SP, Brasil, 4. 
Comissão Econômica para a América Latina e o Caribe - CEPAL. (2016). La matriz de la desigualdad social en América Latina. Santiago: o autor.

Comissão Econômica para a América Latina e o Caribe- CEPAL. (2017). Panorama social da América Latina. Santiago: o autor.

Costa, J. S., Pinheiro, L., Medeiros, M., \& Queiroz, C. (2005). A Face Feminina da Pobreza: Sobre Representação e Feminização da Pobreza no Brasil. Brasília, DF: IPEA. Recuperado de http://www.ipea.gov.br/portal/index. php?option=com_content\&view=article\&id=4726

Crenshaw, K. (1989). Demarginalizing the intersection of race and sex: A black feminist critique of antidiscrimination doctrine, feminist theory, and antiracist politics. University of Chicago Legal Forum, (1), 39-52.

Crenshaw, K. (1991). Mapping the margins: Intersectionality, identity politics, and violence against women of color. Stanford Law Review, 43(3), 1241-1299.

Crenshaw, K. (2004). A intersecionalidade na discriminação de raça e gênero. In: Acaoeducativa.org.br. (Org.), Cruzamento: Raça e gênero (pp. 7-16). Brasília, DF: Ação Educativa.

Daly, K. (2006). Feminist thinking about crime and justice. In: S. Henry, \& M. Lanier (Eds.), The Essential Criminology Reader (pp. 205-213). Boulder: Westview Press.

Davis, A. (2003). Are prisons obsolete? New York, NY: Open Media, Seven Stories Press.

De Coster, S., \& Heimer, K. (2017). Choice within constraint: An explanation of crime at the intersections. Theoretical Criminology, 21(1), 11-22. https://doi.org/10.1177/1362480616677494

Del Olmo, R. (1998). Reclusion de mujeres por delitos de drogas: Reflexiones iniciales. Revista Española de Drogodependencias, 23(1), 5-24.

Diniz, D. (2015). Cadeia: Relatos sobre mulheres. Rio de Janeiro: Civilização Brasileira.

Espinoza, O. M. (2004). A mulher encarcerada em face do poder punitivo (Dissertação de mestrado). Faculdade de Direito, Universidade de São Paulo, São Paulo, SP, Brasil.

Foucault, M. (1987). Vigiar e punir: Nascimento da prisão (R. Ramalhete, Trad.). Petrópolis: Vozes. (Obra original publicada em 1975).

Flausina, A. L. P. (2008). Corpo negro caído no chão: O sistema penal e o projeto genocida do Estado brasileiro. Rio de Janeiro, RJ: Contraponto.

Giacomello, C. (2013). Mujeres, delitos de drogas y sistemas penitenciarios en América Latina. Documento Informativo do IDCP. Recuperado de https:/ /www.unodc.org/documents/congress/background-information/NGO/ IDPC/IDPC-Briefing-Paper_Women-in-Latin-America_SPANISH.pdf

Goffman, E. (2010). Manicômios, prisões e conventos. São Paulo: Perspectiva

International Centre for Prison Studies - ICPS. (2015). World prison population list. London:WPB.

International Centre for Prison Studies-ICPS. (2017). World Female Imprisonment List (4a ed.). London: WPB. Recuperado de: http://www.prisonstudies.org/about-wpb

Lei No 11.343, de 23 de agosto de 2006. Institui o Sistema Nacional de Políticas Públicas sobre Drogas - Sisnad; prescreve medidas para prevenção do uso indevido, atenção e reinserção social de usuários e dependentes de drogas; estabelece normas para repressão à produção não autorizada e ao tráfico ilícito de drogas; define crimes e dá outras providências. Diário Oficial da União, 24 ago. 2006.

Maluf, S. W. (2014). Prefácio. In: V. Zanello, \& A. P. M. Andrade (Org.), Saúde mental e gênero: Diálogos, práticas e interdisciplinaridade. Curitiba, PR: Appris.

Mendes, S. R. (2014). Criminologia feminista: Novos paradigmas. São Paulo, SP: Saraiva.

Moura, M. J. (2005). Porta fechada, vida dilacerada - mulher, tráfico de drogas e prisão: Estudo realizado no presídio feminino do Ceará (dissertação de mestrado). Universidade Estadual do Ceará, Fortaleza, Ceará, Brasil.

Owen, B., Wells, J., \& Pollock, J. (2017). Intersectional inequality and women's imprisonment. In: B. Owen, J. Wells, \& J. Pollock, In search of safety: Confronting inequality in women's imprisonment (pp. 1-18). Oakland, CA: University of California Press. 
Paik, L. (2017). Critical perspectives on intersectionality and criminology: Introduction. Theoretical Criminology, 21(1), 4-10. https://doi.org/10.1177/1362480616677495

Pateman, C. (1993). O contrato social:Papeis sexuais. São Paulo, SP: Paz e Terra.

Pires, T. R. O. (2013). Criminalização do racismo entre política de reconhecimento e meio de legitimação do controle social dos não reconhecidos (Tese de doutorado). Pontifícia Universidade Católica do Rio de Janeiro, Rio de Janeiro, Brasil.

Portella, A. P. F. G. (2014). Como morre uma mulher? Configurações da violência letal contra mulheres em Pernambuco (Tese de doutorado). Programa de Pós-Graduação em Sociologia, Universidade Federal de Pernambuco, Recife, PE, Brasil.

Potter, H. (2013). Intersectional criminology: Interrogating identity and oower in criminological research and theory. Critical Criminology, 21(3), 305-318. https://doi.org/10.1007/s10612-013-9203-6

Queiroz, N. (2015). Presos que menstruam. Rio de Janeiro, RJ: Record.

Reishoffer, J. C., \& Bicalho, P. P.(2017). Exame criminológico e psicologia: Crise e manutenção da disciplina carcerária. Fractal, Revista de Psicologia, 29(1), 34-44. https:// doi.org/10.22409/1984-0292/v29i1/1430

Rotelli, F., De Leonardis, O., \& Mauri, D. (2001). Desinstitucionalização, uma outra via: A reforma psiquiátrica italiana no contexto da Europa Ocidental e dos "países avançados". In: F. Rotelli, O. De Leonardis, \& D. Mauri. (Org.), Desinstitucionalização (2a ed., pp. 17-59). São Paulo, SP: Hucitec

Rubin, G. (1975). O tráfico de mulheres: Notas sobre a "economia política" do sexo (C. R. Dabat, E. O. Rocha, \& S. Correa, Trad.). Recife, PE: SOS Corpo.

Saffioti, H. (2004). Gênero, patriarcado, violência. São Paulo, SP: Perseu Abramo.

Scott, J. W. (1995). Gênero: Uma categoria útil de análise histórica. Educação \& Realidade, 20(2), 71-99.

Silva, S. L. (2017). Mulheres e criminalidade: Aspectos de uma inclusão enviesada. Revista Transgressões: Ciências Criminais em Debate, 5(2), 104-118.

Silveira, R. S., \& Nardi, H. C. (2014). Interseccionalidade gênero, raça e etnia e a lei Maria da Penha. Psicologia \& Sociedade, 26(Esp.), 14-24. https://doi.org/10.1590/S0102-71822014000500003

Wacquant, L. (1999). As prisões da miséria. Paris: Raisons d'Agir.

Washington Office on Latin America - WOLA, \& Transnational Institute - TNI. (2010). Sistemas sobrecargados: Leyes de drogas y cárceles en América Latina. Washington, DC: WOLA/TNI.

Zaffaroni, E. R. (1993). La mujer y el poder Punitivo. In: A. F. Motejo (Org.), Sobre patricarcas, jeararcas, patrones y otros varones: Una mirada genero sensitiva del Derecho (Proyecto Mujer e Justicia Penal, pp. 89-101). San José, CR: Ilanud.

\section{Idilva Maria Pires Germano}

Psicóloga e Doutora em Sociologia pela Universidade Federal do Ceará (UFC), Fortaleza - CE. Brasil. Professora Titular do Departamento de Psicologia da UFC e docente pesquisadora do Programa de Pós-Graduação em Psicologia da UFC. Tutora do Programa de Educação Tutorial (PET - Psicologia) na UFC.

E-mail: idilvapg@gmail.com

(iD https://orcid.org/0000-0003-0062-9899

\section{Rebeca Áurea Ferreira Gomes Monteiro}

Psicóloga. Bolsista do PET-Psicologia UFC (2015-2018). Graduada em Psicologia pela Universidade Federal do Ceará (UFC), Fortaleza - CE. Brasil. E-mail: rebeca.am@hotmail.com

(iD https://orcid.org/0000-0002-4953-7082 
Mariana Tavares Cavalcanti Liberato

Psicóloga. Doutora em Psicologia pela Universidade Federal do Rio Grande do Norte (UFRN), Natal - RN. Brasil. Professora Adjunta do Departamento de Psicologia da Universidade Federal do Ceará (UFC), Fortaleza - CE. Brasil. E-mail: mariana_liberato@yahoo.com.br

(iD) https:// orcid.org/0000-0002-9410-0437

Endereço para envio de correspondência:

Departamento de Psicologia da Universidade Federal do Ceará (UFC)

Av. Da Universidade 2762

Area 2 do Centro de Humanidades

Bloco Ícaro Moreira

Bairro Benfica- CEP 60020-180

Fortaleza- CE

Recebido 19/08/2018

Aprovado 23/08/2018

Received 08/19/2018

Approved 08/23/2018

Recibido 19/08/2018

Aceptado 23/08/2018

Este trabalho contou com o apoio de bolsas concedidas à la e 2a autoras pelo Fundo Nacional de Desenvolvimento da Educação - (FNDE/MEC) do Programa de Educação Tutorial- PET-Psicologia.

Como citar: Germano, I. M. P., Monteiro, R. A. F. G., \& Liberato, M. T. C. (2018). Criminologia crítica, feminismo e interseccionalidade na abordagem do aumento do encarceramento feminino. Psicologia: Ciência e Profissão, 38(n.spe.2), 27-43. https://doi.org/10.1590/1982-3703000212310

How to cite: Germano, I. M. P., Monteiro, R. A. F. G., \& Liberato, M. T. C. (2018). Critical criminology, feminism and Intersectionality to approach the rise of female incarceration. Psicologia: Ciência e Profissão, 38(n.spe.2), 27-43. https://doi.org/10.1590/1982-3703000212310

Cómo citar: Germano, I. M. P., Monteiro, R. A. F. G., \& Liberato, M. T. C. (2018). Criminología crítica, feminismo e interseccionalidad en el abordaje del aumento del encarcelamiento femenino. Psicologia: Ciência e Profissão, 38(n.spe.2), 27-43. https://doi.org/10.1590/1982-3703000212310 